\title{
Neurobehavioural effects of exposure of wistar rats to smoke from traditional Carica papaya (pawpaw) leaves
}

\author{
Aboyeji Lukuman Oyewole, Bamidele Victor Owoyele* \\ Department of Physiology University of Ilorin, Ilorin, Nigeria
}

\begin{abstract}
This study was carried out to investigate the neurobehavioural effects of the smoking of Carica papaya leaves based on ethnopharmacological information. Twenty -four rats used for the study were grouped into four groups namely; Groups 1 (Control, unexposed to any smoke) and Groups 2 - 4 (exposed to smoke from varying amount of pawpaw leaf powder). Groups 2, 3, and 4 were exposed to smoke from $6.25 \mathrm{~g}$ (low dose), $12.50 \mathrm{~g}$ (medium dose), and $18.75 \mathrm{~g}$ (high dose) of dry pawpaw leaves respectively in a smoking chamber twice daily for 21 one days with each exposure lasting $3 \mathrm{~min}$. The spontaneous motor activities and locomotory behaviour of the animals were assessed using an open field maze and hole board maze test. The results showed that the smoking of Carica papaya leaves led to a significant ( $p<$ 0.05 ) increase in locomotory activities from $33.36 \pm 3.36$ (control) to $66.50 \pm 6.16$ (high dose), number of head dips (from $8.50 \pm 0.36$, to $12.83 \pm 0.87$ ) and rearing behaviour (from $14.83 \pm 0.74$, to $27.0 \pm 1.46$ ). However, the freezing durations as animals were introduced into the maze and grooming behaviour were significantly $(p<0.05)$ reduced in the treated groups. In conclusion, the increased ambulations and exploratory behaviours imply that the anxiety level is low in the treated groups compared to the control group which thus confirms that dry Carica papaya leaf may possibly contain psychoactive substance(s) that become active when smoked.
\end{abstract}

Keywords Anxiety, Carica papaya, hole board test, maze test, neurobehaviour, rats, smoke

\section{INTRODUCTION}

Carica Papaya (pawpaw) plant is a tropical plant that probably originated from Southern Mexico and Central America. It is now commonly cultivated in tropical and subtropical regions worldwide in farms and gardens (Monti et al., 2004) including Nigeria. It is a member of the family caricaceae (Dallwitz, 1980). The ripe fruit of the pawpaw plant is commonly consumed as food in different parts of the world (Maniyar and Bhixavatimath, 2012; Oduola, 2007). In addition, it is a medicinal plant that is used for the treatment of many ailments. Its leaves can be used as a poultice on boils and wounds. Likewise, information from the literature has shown that the extract of the leaves can be used for the treatment of pain, inflammations and ulcers (Gill, 1992; Owoyele et al., 2008). Recent studies show that the leaves have antiplamodial, antifungal antihyperglycaemic, antitumor and hypolipidemic activities (Chavez-quintal et al., 2011; Maniyar and Bhixavatimath, 2012; Melariri et al., 2011; Otsuki et al., 2010). Carpaine, (an alkaloid) which is the main active ingredient in pawpaw has been linked with poisoning of the heart and depressing the central nervous system (CNS) (Burdick, 1971; Joshi et al., 1996). However, despite its previously reported CNS effect, there is information in the literature showing that the smoking of Carica Papaya leaves can relieve asthma and probably is a CNS stimulant (Okoli et al., 2007; Olley, 2007).

Many substances affect the functions of the brain by serving

*Correspondence: Owoyele Bamidele Victor

E-mail: deleyele@yahoo.com or owoyele@unilorin.edu.ng

Received September 7, 2012; Accepted November 21, 2012;

Published Novemver 30, 2012

doi: http://dx.doi.org/10.5667/tang.2012.0035

(C)2012 by Association of Humanitas Medicine

TANG / www.e-tang.org as depressants or stimulants. Such psychoactive substances include caffeine, cannabis and nicotine among others which are derived from plant products (Carlini, 2003; Nawrot et al., 2003; Olley, 2007). A timely investigation about a novel psychoactive agent will provide information about the agent not only to the users but also to the world at large and therefore help in policy formulation. Carica papaya leaf is smoked and yet we have no scientifically documented information about its possible stimulatory effect on the brain other than the survey carried out by Olley (2007). The survey obtained the views of 500 students of the University of Ibadan in Nigeria and the analysis of the results showed that the majority of the respondents believed that smoking the leaves of Carica papaya probably has psychoactive effects and this could be dangerous to the smokers' health. About $43 \%$ of the respondents believed that the effects of Carica papaya leaf smoking resemble those of cannabis with $32 \%$ claiming that the effects resemble those of heroin or cocaine. Olley called for further investigation on the effect of the smoking of the leaves of the plant (Olley, 2007).

The present study was therefore, undertaken to specifically investigate if the smoking of the dry leaves of Carica papaya has any neurobehavioural effects in rats which might be an indication for its possible effects in people who smokes the leaves of the plant. This study is one of the first attempts to scientifically use animal models to investigate the traditional practices (of smoking Carica papaya leaves) by some smokers in Nigeria, and the study was design to mimic the smokers' activities by trying to expose animals to the equivalent amount of leaves used for smoking by an average smoker.

\section{MATERIALS AND METHODS}

2012 / Volume 2 / Issue 4 / e36 


\section{Plant preparation}

Dry Carica papaya leaves were collected at the outskirt of University of Ilorin, Kwara State, Nigeria (N 8 $8^{\circ} 29^{\prime} 30.228^{\prime \prime}$, E $\left.4^{\circ} 32^{\prime} 40.6968^{\prime \prime}\right)$ in April of 2010. The plant has been identified previously (Owoyele et al., 2008) at the Forestry Research Institute of Nigeria with a herbarium number FHI 106933. The amounts of leaves to be collected as well as the dosages of leaves to be smoked were determined from information obtained from pawpaw smokers in the Ilorin metropolis which showed that the Carica papaya leaf smokers could only smoke a maximum of one whole leaf at a time. Meanwhile, the size of a pawpaw leaf varies; thus forty (40) whole dry pawpaw leaves were gathered. The spines of the harvested dry leaves were removed so that only the spineless sections of the leaves remained. This was done in accordance with information from actual smokers that indicate that papaya leaf smokers would smoke only the leaves without the spines. The entire forty (40) leaves that were used for this study weighed $500 \mathrm{~g}$, thus indicating that an average weight of a leave was $12.50 \mathrm{~g}$. The leaves were thereafter powdered and then measured into different dosages for the study. Dosages include low dose (6.25 $\mathrm{g})$, medium dose (12.50 g) and high dose (18.75 g); these dosages fairly correspond to half a leaf, a whole leaf; and a whole and half leave respectively.

\section{Animals}

Twenty-four adult male wistar rats of an average weight of 232.0 $\pm 5.0 \mathrm{~g}$ were used for this investigation. They were housed and bred in the animal house of the Faculty of Basic Medical Sciences, College of Health Sciences, university of Ilorin, Nigeria. The animals were kept in standard cages with good ventilation and environmental conditions. Prior and during the research period, the animals were allowed free access to feeds (mouse pellet) and clean water. Ethical guidelines of the College of Health Sciences, University of Ilorin on animal's experiment were strictly followed. These guidelines are in accord with the internationally accepted principles for laboratory animal use and care.

The rats were randomly grouped into 4 groups with six rats forming a group and were allowed to acclimatize for seven days. On the last day of acclimatization, each group was labeled as following: control group, low dose group, medium dose group and high dose group. Animals in the control group were given nothing. The low dose group was exposed to smoke from dry pawpaw leaf of $6.25 \mathrm{~g}$. The medium dose group was exposed to smoke from dry pawpaw leaf of $12.50 \mathrm{~g}$ while the high dose group was exposed to smoke from dry pawpaw leaf of $12.75 \mathrm{~g}$. Each rat in the tested groups (i.e. low dose, medium dose and high dose group) was exposed individually to smoke from dry Carica papaya leaf. This was done in a smoking chamber. The smoking chamber used is three column chambers of total height of about $0.3 \mathrm{~m}$. Each of the chambers is perforated so that smoke can get from one chamber to the other. The first chamber has an attached electric burner that burns the leaves used and the chamber itself acts as an heat absorber, absorbing heat generated from the burner. The second chamber acts as the heat breaker, limiting the heat that gets to the third chamber and the third chamber accommodates the rat used. At the top of the third chamber, there is an outlet of $5 \mathrm{~cm}$ in diameter through which the smoke escapes into the air. Exposure duration was 3 min twice per day. The procedure (exposure to Carica papaya smoke) was repeated for 21 days.

\section{Neurobehavioural studies}

Open field maze test: The open field apparatus used in the present study consisted of a square area $(72 \times 72 \mathrm{~cm})$ with walls $36 \mathrm{~cm}$ high. The four walls were made with transparent Plexiglas. The wooden floor was painted white; it was divided by lines into 16 equal squares by parallel and intersecting blue lines. A central square was drawn in the middle of the open field (Bhattacharya and Satyan, 1997). The entire apparatus was raised $50 \mathrm{~cm}$ above the ground level. Twenty one days after dual daily exposure of the treated groups, neurobehavioural activities were evaluated by placing a rat singly in the central square of the open field maze. The following parameters were observed during the $15 \mathrm{~min}$ exposure period of both the control and the treated animals: (i) ambulation (ii) rearing (iii) grooming duration and (iv) freezing latency (upon placing the animals into the central square).

\section{Hole board maze test}

The rat hole board maze apparatus was a wooden box with a floor $66 \mathrm{~cm}$ x $56 \mathrm{~cm}$ and $47 \mathrm{~cm}$ walls high. In the floor, there were 16 equally spaced holes that was $3.8 \mathrm{~cm}$ in diameter. The wooden floor was $1.8 \mathrm{~cm}$ thick and the whole apparatus was 40 $\mathrm{cm}$ raised from the ground (File and Wardill, 1975). Each animal was placed in the centre of the hole board apparatus facing away from the observers. Its behavioural activity particularly the number of head dips was recorded for $15 \mathrm{~min}$. A head dip was scored if both eyes disappeared into the hole. Unlike in mice, stereotypic action was documented to be absent in rat. Therefore, repeated head dips in the same hole were scored

\section{Statistical analysis}

In this research, values were expressed as mean \pm standard error of mean (S.E.M.) and analysis was carried out by using a one way analysis of variance (ANOVA) at a statistical significant level of $p<0.05$.

\section{RESULTS}

Effect of pawpaw leaf smoking on anxiety behaviour in the open field maze

The results of the effect of smoke from pawpaw leaves on anxiety behaviours in the open field maze show that the smoke dose dependently increased ambulations from $33.33 \pm 3.36$ to $66.50 \pm 6.16$ (Table 1) and rearing behaviours (from 14.83 \pm

Table 1. Effect of Carica papaya leaf smoking on ambulations in wistar rats using open field maze

\begin{tabular}{lc}
\hline Groups & Ambulations $^{\mathrm{a}}$ \\
\hline Control & $33.33 \pm 3.36$ \\
C. papaya $(6.25 \mathrm{~g})$ & $47.50 \pm 2.80^{*}$ \\
C. papaya $(12.50 \mathrm{~g})$ & $53.67 \pm 3.92^{*}$ \\
C. papaya $(18.75 \mathrm{~g})$ & $66.50 \pm 6.16^{*}$
\end{tabular}

${ }^{\mathrm{a}}$ Each value is the mean \pm S.E.M. of 6 rats. C. papaya, Carica papaya. ${ }^{*} p<0.05$ compared with control; ANOVA.

Table 2. Effect of smoke from dry Carica papaya leaf on exploratory behaviour in wistar rats on the open field maze

\begin{tabular}{lccc}
\hline Groups & Rearing $^{\text {a }}$ & Grooming $(\mathbf{s})$ & Freezing (s) \\
\hline Control & $14.83 \pm 0.74$ & $46.42 \pm 2.74$ & $18.44 \pm 0.85$ \\
C. papaya $(6.25 \mathrm{~g})$ & $18.17 \pm 0.98^{*}$ & $29.06 \pm 0.68^{*}$ & $5.69 \pm 0.43^{*}$ \\
C. papaya $(12.50 \mathrm{~g})$ & $20.83 \pm 1.35^{*}$ & $26.54 \pm 2.39^{*}$ & $8.29 \pm 0.32^{*}$ \\
C. papaya $(18.75 \mathrm{~g})$ & $27.0 \pm 1.46^{*}$ & $21.27 \pm 1.32^{*}$ & $8.51 \pm 0.50^{*}$ \\
\hline
\end{tabular}

${ }^{\mathrm{a}}$ Each value is the mean \pm S.E.M. of number of rearing by 6 rats. C. papaya, Carica papaya. ${ }^{*} p<0.05$ compared with control; ANOVA. 
0.74 to $27.0 \pm 1.46$ ) in the treated groups compared to the control group (Table 2). Grooming and freezing durations on immediate introduction into the maze were significantly $(p<0.05)$ but did not dose dependently decreased (Table 2).

Effect of pawpaw leaf smoking on anxiety behavior in the hole board maze

The results obtained from this model shows that pawpaw leaf smoking significantly $(p<0.05)$ increased the number of head-dips in the treated groups from $8.50 \pm 0.36$ (control group) to $13.33 \pm 1.15$ (medium group) on the hole board maze (Table $3)$.

Table 3. Effect of Carica papaya leaf smoking on head-dip behaviour in wistar rats using hole board maze

\begin{tabular}{lc}
\hline Groups & Total head-dip $^{\mathbf{a}}$ \\
\hline Control & $8.50 \pm 0.36$ \\
C. papaya $(6.25 \mathrm{~g})$ & $11.50 \pm 0.62^{*}$ \\
C. papaya $(12.50 \mathrm{~g})$ & $13.33 \pm 1.15^{*}$ \\
C. papaya $(18.75 \mathrm{~g})$ & $12.83 \pm 0.87^{*}$ \\
\hline
\end{tabular}

${ }^{\mathrm{a}}$ Each value is the mean \pm S.E.M. of number of head dips by 6 rats. $C$ papaya, Carica papaya. ${ }^{*} p<0.05$ compared with control; ANOVA.

\section{DISCUSSION}

Exploratory behaviour in animals can be assessed using an open field maze (Holmes et al., 2002). This is done by exploiting the fact that animals removed from their cages to another environment usually express anxiety and fear. This causes alterations in all or some parameters such as decreases in ambulation and exploration and immobilization or freezing. All these are due to augmented autonomic activity in the animals (Bhattacharya et al., 1991; Novas et al., 1988). The use of locomotor and explorative activities in laboratory animals to evaluate the gross behavioural effects of drugs has been proven and found trust worthy (Carpenedo et al., 1994). This is believed to correlate well with drugs effects in humans. In addition to this, activities such as ambulations (line crossing), rearing and walling in rats are used in measuring locomotor and exploration activities as mentioned above as well as anxiety; an increase in the frequency of these activities indicates increased locomotion, exploration and low anxiety (Walsh and Cummins, 1976).

In the present study, activities in the open field maze showed a dose dependent increase in both ambulations and rearing activities hence low anxiety in the exposed groups (Mesembe et al., 2009; Walsh and Cummins, 1976). Despite this general observation, ambulatory activities were only significantly ( $p<$ 0.05 ) increased in the medium and high dose groups compared with the control group. Also, the freezing durations on the first introduction into the maze were significantly $(p<0.05)$ decreased in the treated groups compared to the control group. The decrease in freezing duration as well as the increase in ambulatory activities are an indication of the anxiolytic effect of smoking Carica papaya. This inference is also supported by the findings of Perveen et al. which showed that the increased in ambulation in the open field maze was as a result of the anxiolytic effect of Nigella. sativa administered to treated groups (Perveen et al., 2009).

The anxiolytic effects observed after inhalation of smoke from dry Carica papaya leaf is possibly due to the presence of flavonoids, alkaloids and terpernoids in the plant (Owoyele et al, 2008). These chemical constituents are found in various plants and have been linked with anxiolytic and sedative effects (Carlini, 2003; Dhawan et al., 2001). Further study is however necessary to detect not only the combustive products of the above mentioned ingredients in Carica papaya but also to single out whether the activity is due to a particular class of the active agents such as alkaloids. This is because carpaine an alkaloid in Carica papaya has been linked with depression of CNS activities (Burdick, 1971; Joshi et al., 1996) which tend to be at a variance with our findings.

The findings from the open field maze were confirmed in the hole board maze where the number of head-dips in the treated groups significantly increased in the medium and high dose groups when compared with the control group. Interestingly, smoking a high dose of Carica papaya did not produce significantly different head dips compared with the medium dose; this probably showing that the medium amount was the optimum dose for the responses in this test. It is not uncommon to find such pattern of responses; for instance, $\mathrm{Su}$ showed ( $\mathrm{Su}$, 1982) that CNS is stimulated by a low nicotine dose while Henningfield et al. reported the depression of CNS by nicotine at a high dose (Henningfield et al., 1985). In contrast, the grooming activity was significantly $(p<0.05)$ reduced with the increasing dosage of Carica papaya when compared with the control group. This suggests that Carica papaya smoking might have another ability to act as a selective agonist of $D_{2}$ receptors because other authors have documented that the $\mathrm{D}_{2}$ receptor agonist has the ability to reduce grooming behaviour in human and different animals (Briley et al., 1990; Ferari et al., 1992).

In conclusion, this investigation confirms the general belief that dry pawpaw leaf smoking is psychoactive. This might be due to the presence of some constituents of the leaves that can become active when smoked. The psychoactive substance(s) reduces anxiety level in rats and ultimately this might be what happens with people who smoke Carica papaya leaves. Further studies are required to unravel the nature of the active ingredient(s) that is responsible for the neurobehavioural changes observed in this study as well as the possible neurohistological and biochemical effects of smoking the leaves of this plant.

\section{CONFLICT OF INTEREST}

The authors have declared no conflict of interest.

\section{REFERENCES}

Bhattacharya SK, Clow A, Przyborowska A, Halket J, Glover V, Sandler M. Effect of aromatic amino acids, pentylentetrazole and yohimbine on isatin and tribulin activity in rat brain. Neurosci Lett. 1991;132:44-46.

Bhattacharya SK, Satyan KS. Experimental methods for evaluation of psychotropic agents in rodents: I-antianxiety agents. Indian J Exp Biol. 1997;35:565-575.

Briley M, Chopin P, Moret C. Effect of serotonergic lesion on "anxious" behaviour measured in the elevated plus maze test in the rat. Psychopharmacol (Berl). 1990;101:187-189.

Burdick EM. Carpaine: An alkaloid of Carica papaya - Its chemistry and pharmacology. Econ. Bot. 1971;25:363-365.

Carlini EA. Plants and the central nervous system. Pharmacol, Biochem Behav. 2003;75:501-512.

Carpenedo R, Chiarugi A, Russi P, Lombardi G, Carlà V, Pellicciari, R, Mattoli L, Moroni F. Inhibitors of Kynurenine hydroxylate and Kynureniase increase cerebral formation of 
Kynueniase and have sedative and anti-convulsant activities. Neurosci. 1994;61:237-243.

Chávez-Quintal P, González-Flores T, Rodríguez-Buenfil I, Gallegos-Tintoré S. Antifungal Activity in Ethanolic Extracts of Carica papaya L. cv. Maradol Leaves and Seeds. Indian J Microbiol. 2011;51:54-60.

Dallwitz MJ. A general system for coding taxonomic descriptions. Taxon.1980;29:41-46.

Dhawan K, Kumar S, Sharma A. Anti anxiety studies on extracts of Passiflora incernata Linneaus. J Ethnopharmacol. 2001;78:165-170.

Ferrari F, Pelloni F, Giuliani D. Suppressive effect of the dopamine $\mathrm{D}_{2}$ receptor against B-HT 920 on rat grooming. Eur J Pharmacol. 1992;216:345-350.

File SE, Wardill AG. Validity of head-dipping as a measure of exploration in a modified hole board. Psychopharmacol. 1975;44:53-59.

Gill LS. Ethnomedical Uses of Plants in Nigeria. (Benin City, Nigeria: Uniben Press), pp. 269-276, 1992.

Henningfield JE, Miyasato K, Jasinski DR. Abuse liability and pharmacodynamic characteristics of intravenous and inhaled nicotine. J Pharmacol Exp Ther. 1985;234:1-12.

Holmes A, Wrenn CC, Harris AP, Thayer KE, Crawley JN. Behavioural profiles of inbred strains on novel olfactory, spatial and emotional tests for reference memory in mice. Genes Brain Behav. 2002;1:55-69.

Hsieh M, Wu C, Chen C. Gastrodin and p-hydroxybenzyl alcohol facilitate memory consolidation and retrieval, but not acquisition, on the passive avoidance task in rats. $\mathbf{J}$ Ethnophamacol. 1997;56:45-54.

Joshi BS, Newton MG, Lee DW, Barber AD, Pelletier SW. Reversal of absolute stereochemistry of the pyrrolo[2,1-b]quinazoline alkaloids vasicine, vasicinone, vasicinol and vasicinolone. Tetrahedron Asymmetry. 1996;7:25-28.

Maniyar Y, Bhixavatimath P. Antihyperglycemic and hypolipidemic activities of aqueous extract of Carica papaya Linn. leaves in alloxan-induced diabetic rats. J Ayurveda Integr Med. 2012;3:70-74.

Melariri P, Campbell W, Etusim P, Smith P. Antiplasmodial Properties and Bioassay-Guided Fractionation of Ethyl Acetate Extracts from Carica papaya Leaves. J Parasitol Res. 2011;10:49-54.
Mesembe OE, Bisong SA, Ekong MB, Ekeoma AO. Neurobehavioural activity in albino Wistar rats in the open field maze following long term tobacco diet ingestion. The Internet $\mathbf{J}$ Neurol. 2008;10:13.

Monti R, Contiero J, Goulart AJ. Isolation of natural inhibitors of papain obtained from Carica papaya latex. Braz Arch Biol Technol. 2004;47:757-754.

Nawrot P, Jordan S, Eastwood J, Rotstein J, Hugenholtz A, Feeley M. Effects of caffeine on human health. Food addit Contam. 2003;20:1-30.

Novas ML, Wolfman C, Medina JH, Robertis E. Proconvulsant and 'anxiogenic' effects of n-butyl beta carboline-3-carboxylate, an endogenous benzodiazepine binding inhibitor from brain. Pharmacol Biochem Behav. 1988;30:331-336.

Oderinde O, Noronha C, Oremosu A, Kusemiju T, Okanlowan OA. Abortifacient properties of aqueous extract of Carica papaya (Linn) seeds on female Sprague- Dawley rats. Niger postgrad Med J. 2002;9:95-98.

Oduola T, Adeniyi FAA, Ogunyemi EO, Idowu TO, Bello IS. Evaluation of the Effects of Intake of Extract of Unripe Pawpaw (Carica Papaya) on Liver Function in Sickle Cell Patients. World J Med Sci. 2007;2:28-32.

Okoli RI, Aigbe O, Ohaju-Obodo JO, Mensah JK. Medicinal Herbs Used for Managing Some Common Ailments among Esan People of Edo State, Nigeria. Pakistan J Nutri. 2007;6:490-496.

Olley BO. Is dried paw-paw leaf a psychoactive substance. IFI PsychologIA. 2007;15:25-39.

Otsuki N, Dang NH, Kumagai E, Kondo A, Iwata S, Morimoto C. Aqueous extract of Carica papaya leaves exhibits anti-tumor activity and immunomodulatory effects. J Ethnopharmacol. 2010;127:760-767.

Owoyele BV, Adebukola OM, Funmilayo AA, Soladoye AO. Anti-inflammatory activities of ethanolic extract of Carica papaya leaves. Inflammopharmacology. 2008;16:168-173.

Perveen T, Haider S, Kanwal S, Haleem DJ. Repeated administration of Nigella sativa decreases 5-HT turnover and produces anxiolytic effect in rats. Pak $\mathrm{J}$ Pharm Sci. 2009;22:139-144.

$\mathrm{Su}$ C. Actions of nicotine and smoking on circulation. Pharmacol Ther. 1982;17:129-141.

Walsh RN, Cummins RA. The open-field test: a critical review. Psychol Bull. 1976;83:482-504 